29

\title{
Two Models for Introducing Graduate Students to the Scholarship of Teaching and Learning
}

\author{
Natasha Patrito Hannon \\ University of Western Ontario \\ Svitlana Taraban-Gordon \\ University of Waterloo
}

Graduate students aspiring to become faculty members should be provided with meaningful opportunities to explore the scholarship of teaching and learning (SoTL) and to formulate questions about student learning and effective teaching. To this end, teaching and learning centres should incorporate SoTL-oriented components within the framework of educational development programs to prepare our future faculty. This article briefly reviews the emerging literature on graduate student engagement with SoTL and highlights two possible approaches for incorporating So TL into educational development programs for graduate students.

W ith its theoretical roots in Ernest Boyer's Scholarship Reconsidered (1990), the scholarship of teaching and learning (SoTL) movement could be likened to a massive tidal wave, rapidly transforming the educational "seascape." SoTL invites educators to engage in a systematic study of teaching and learning and to make the results of this research public through presentations, performances, or publications (McKinney, 2006). A number of studies have highlighted the individual and institutional benefits that can be derived from SoTL engagement. Surveys of faculty members engaged in SoTL research suggest that these academ- ics experience greater excitement in their teaching and become more interested in broader teaching and learning issues (Ciccone \& Meyers, 2006; Huber \& Hutchings, 2005). Most made changes to course designs and learning assessments in response to their research results, highlighting the integration between classroom research and classroom instruction (Huber \& Hutchings, 2005). Moreover, many of the respondents reported that their SoTL had a positive influence on teaching in their departments beyond their own practice and influenced colleagues outside of their departments (Ciccone \& Meyers, 2006). O’Meara (2005) 
found that institutions that promoted SoTL in addition to traditional disciplinary scholarship reported a heightened campus focus on the quality of undergraduate learning and greater gains in the value associated with teaching in the tenure and promotion process.

In response to the growing momentum of the SoTL movement, teaching and learning centres across Canada have developed programming to equip faculty members with the resources and skills necessary to surf the SoTL wave. Institutions have created funding opportunities, such as the Research on Teaching Small Grants Program at the University of Western Ontario or the President's Teaching \& Learning Scholars Program at the University of Regina, and have established communities of practice, such as the University of Waterloo's Teaching-Based Research Group. With these programs focusing primarily on the needs of current faculty members, the future professoriate - graduate students - remain largely on the periphery of the Canadian SoTL community and risk being trapped in its wake unless resources are developed to engage them in this emerging field of research.

In recent years, several scholars have called for the restructuring of graduate education to enhance the status of SoTL within the academy (Kreber, 2001; McKinney, 2006). Shulman (2004), among others, argues that SoTL should be formally integrated into the graduate experience so that "we may create scholars who learn early on how to elegantly integrate their teaching with their research" (p. 10). The new and evolving nature of SoTL as a mode of inquiry offers educational developers a myriad of programming choices and opportunities; however, it also creates challenges in the graduate training context. Among the most significant is a lack of theoretical frameworks or best practices to guide the development of effective SoTL programs targeted at a graduate audience. Although few such models exist, a particularly useful one, proposed by Gale and Golde (2004), identifies four critical stages of SoTL training for future faculty:

1. Exposure - Graduate students read and cri- tique SoTL research to develop an understanding of the ways in which such work is communicated to the next generation of scholars.

2. Encounter - Graduate students examine, in greater depth, the mechanisms for carrying out SoTL research, such as qualitative and quantitative research approaches, data collection tools, analytical methods, and the peer review process.

3. Engagement - Graduate students engage in their own SoTL design project and carry out independent SoTL research.

4. Extension - Graduate students become mentors for the next cohort of students engaging in SoTL research.

This model could serve as an excellent organizational framework to inform educational developers in their design of graduate student SoTL programming. As new programs emerge, it will be important for developers to examine the specific elements and characteristics of these programs to ensure that students are receiving ample opportunities to engage in all stages of SoTL development. In the following sections, we examine two graduate student SoTL approaches according to the Gale and Golde (2004) framework, assessing their successes and identifying opportunities for further growth.

\section{University of Waterloo: Research Project on a Teaching/Learning}

\section{Issue}

The Centre for Teaching Excellence at the University of Waterloo offers the Certificate in University Teaching (CUT), a campus-wide, comprehensive educational development program for graduate students interested in academic careers. As part of the teaching certificate, the students are asked to complete a small research project about a teaching and/ or learning issue in higher education by drawing on ten articles in teaching periodicals. The goals of the 
research project are to: 1) gain an awareness of the higher education research literature; and 2) communicate a distillation of theories and application of ideas both in written and oral formats (Centre for Teaching Excellence, 2009). A schematic of the four-stage SoTL project incorporated in Waterloo's teaching certificate is presented in Figure 1. This project is based on the premise that graduate students need to be introduced to SoTL in an organized and systematic way with opportunities for feedback and guidance during the key stages of the process.

Graduate students in the certificate program begin their research project by attending a two-hour workshop entitled "Finding Educational Literature," which was developed and is offered in partnership with academic librarians. The workshop introduces them to a range of discipline-specific and interdisciplinary periodicals on teaching and learning and offers hands-on practice in using common education databases. Following the workshop, the students attend a small-group consultation session with the educational developer from the teaching unit. During this session, they share their research topics and research questions, outline the structure of their projects, and talk about the articles that they have consulted. The participants also provide each other with feedback on their projects and share strategies for searching the literature. Upon completion of their literature review, graduate students choose to present their findings in any one of the following formats: 1) a 20-page research paper; 2) a 45 minute workshop; or 3) a research poster. These products are then shared with fellow CUT participants in sessions hosted by the Centre for Teaching Excellence. Each term, five graduate students present their completed research projects. The topics selected by students range from discipline-specific questions about teaching and learning to broader dilemmas of teaching in higher education. As an example, this past year one graduate student reviewed the literature on various models of multiple-choice testing and introduced a new model for designing multiple-choice assessments. Another graduate student examined the literature on grade inflation in Canadian universities and, drawing on current information from the registrar, compared these findings to the situation at the Uni- versity of Waterloo. Some students were able to disseminate the outcomes of their projects at colloquia, conferences and campus-based publications.

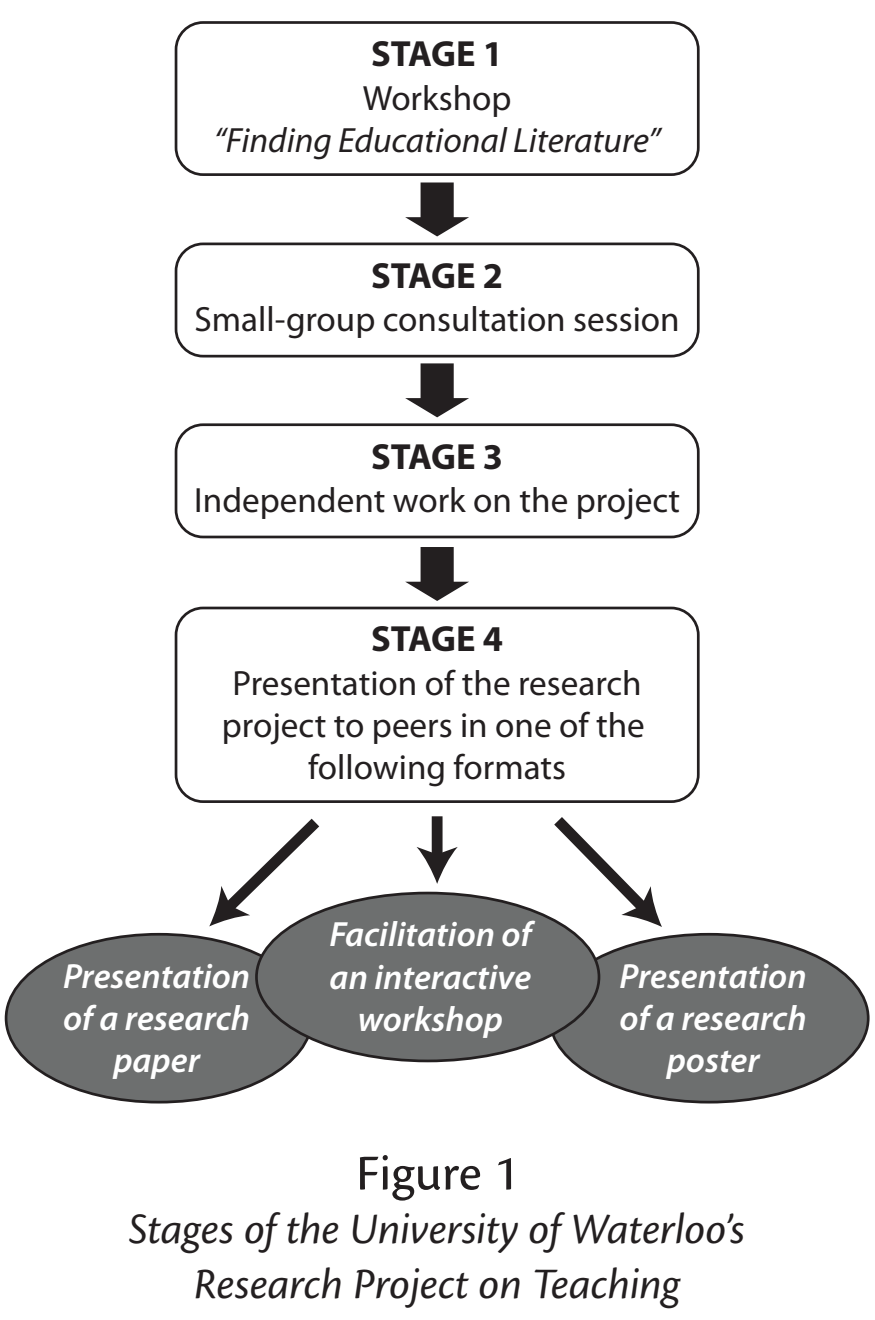

\section{University of Western Ontario: Advanced Teaching Program Capstone Project}

The Advanced Teaching Program (ATP), one of a number of intensive teacher development programs available to graduate students through the Teaching Support Centre (TSC) at the University of Western Ontario, is designed to address the specific needs of experienced teaching assistants (TAs) interested in transitioning into the role of independent instructor. Successful completion of the ATP requires the fulfillment of three distinct program elements: 1) at- 
tendance at a workshop series that highlights, among other topics, the development of learning outcomes, the establishment and maintenance of classroom civility, and authentic assessment of student learning; 2) participation in two unique role-playing sessions where graduate students have the opportunity to respond to challenging classroom situations in the moment and receive feedback from a small group of peers and an experienced facilitator; and 3) preparation and presentation of a one-hour seminar about discipline-specific teaching innovations or challenges to members of their home department.

This third element of the program, called the capstone project, offers graduate students concrete opportunities to explore SoTL literature and to act as ambassadors of scholarly teaching in their departments. To complete the capstone project, participants submit a 3-5 page seminar proposal that includes a review of at least five teaching-related scholarly articles. Similar to the Waterloo model, participants have opportunities throughout ATP to gain feedback on their developing proposal from both peers and ATP instructors. Upon submission of the finalized proposal, graduate students engage in a 45-minute one-on-one consultation with an educational developer to discuss the SoTL underpinnings of their seminar, receiving both oral and written feedback.

Instructional developers then work closely with these graduate students and departments to identify appropriate venues for the presentation of the student seminars. In the past year, two such workshops ("Primary Literature School: Helping Science \& Social Science Students Decode Research" and "TA Evaluations: Getting, Interpreting \& Acting on Formative Feedback") were presented at the campus-wide Winter Conference on Teaching; a third ("Impostor Syndrome: Strategies for Rising Above") was presented as part of the physics department graduate student colloquium; and a fourth ("Writing to Learn: Exploratory Writing in the Undergraduate Classroom") was presented to a mixed group of faculty and graduate students at a philosophy brown-bag lunch seminar series. In this way, graduate students share the SoTL literature with numerous colleagues across campus while building strong and synergistic links to existing campus-wide programs offered through Western's Teaching Support Centre.

\section{Common Characteristics of the Two Projects}

One of the defining features of both projects is the comprehensive mentoring that graduate students receive at all stages of the research process. From introductory workshops on the exploration of education-related periodicals through in-depth, one-on-one consultations about seminar proposals, graduate students' forays into SoTL literature are organized as a series of well-defined and guided steps designed to make the task of navigating SoTL research less daunting.

Implicit in both projects is the notion that graduate students have the potential to be enthusiastic, creative, and dynamic proponents of SoTL in the wider university community. Thus, their projects are presented in public venues to inform and spark discussion among interested colleagues. Both the presenting graduate students and their audience gain pedagogical knowledge, while simultaneously gaining insights into SoTL methodologies and research approaches. Informal conversations with participants of both the CUT and ATP programs also reveal that the skills and knowledge developed through the completion of these projects prove helpful during their search for faculty positions. Several program participants incorporated their disciplinespecific understanding of the SoTL literature into their teaching philosophy statements and teaching portfolios; some discussed these ideas with hiring committees during academic interviews.

While project models at both Western and Waterloo offer participants opportunities to explore and critique the SoTL literature and communicate their understandings to the academic community, graduate students are not required to design or carry out their own research studies. Thus, both projects function largely at the Exposure and Encounter levels of the Gale and Golde (2004) model. Achieving greater graduate student participation at the Engage and Extend levels will require that greater efforts be made to communicate the benefits of practicing SoTL work to this cohort and that opportunities be made available for graduates to participate in genuine SoTL research. Currently, no formal mechanisms 
exist at either institution for graduate students to be mentored by faculty engaging in SoTL research, nor can graduate students apply directly to receive internal funding in support of a SoTL project. To encourage greater SoTL involvement by graduate students, these institutions might consider, among numerous options, formal inclusion of interested graduate students in SoTL research communities, the development of workshops about SoTL research methodologies specifically targeted to graduate students, the establishment of panel sessions facilitated by faculty members engaging in SoTL research, and the creation of online resources highlighting the benefits of engaging in SoTL work.

\section{Continued Opportunities for Growth and Expansion}

As evidenced by our recent presentations at the 2009 Society for Teaching and Learning in Higher Education (STLHE) conference and those of several colleagues at other national and international conferences, there is a growing interest among Canadian educational developers to share ideas and strategies for engaging graduate students in SoTL. While graduate student programs with a SoTL focus are emerging across the country, much of the development is occurring at a "grass roots level" (Christensen Hughes, 2006) with little communication among educational developers and between centres. In comparison, colleagues in the US are quickly embarking on collaborative initiatives including the formation of a multi-institutional Carnegie Academy's for the Scholarship of Teaching and Learning (CASTL) Student Voice in SoTL Group and the publication of a text co-authored by faculty and students entitled Engaging Student Voices in the Study of Teaching and Learning (Werder \& Otis, 2009). To our knowledge, such formal, multi-institutional conversations and networks around graduate student engagement in SoTL have yet to emerge within the Canadian context.

Through discussions initiated at STLHE 2009, the authors of this paper - educational developers who work closely with graduate students realized that they shared common interests and faced a number of common challenges when implementing SoTL programming at their institutions and that these issues could be of relevance to other developers in Canada. A brief review of some of the Canadian teaching training programs with a SoTL component suggests that there are significant variations in models and approaches used to introduce graduate students to SoTL. These variations are particularly evident in the following areas: 1) the extent to which graduate students are exposed to the SoTL literature and engage in SoTL research; 2) the types of SoTL projects undertaken by graduate students; 3 ) the support provided to graduate students conducting SoTL projects; and 4) the requirements for dissemination of project results.

To our knowledge, no attempts have been made by Canadian educational developers to formally document these approaches, examine their effectiveness or assess the impact of SoTL projects on the academic careers of graduate students. With the support of an Educational Developers Caucus grant, the authors have embarked on a research project that aims to create a national "map" of current SoTL initiatives aimed at graduate students. Using a combination of surveys and in-depth interviews, we are documenting SoTL engagement models emerging from different institutions, uncovering challenges that may be hindering the delivery of such programming to graduate students, highlighting opportunities for the creation of additional programming, and identifying potential synergies and collaborations among developers working in this area. We look forward to sharing the results of this research with the higher education community at STLHE 2010.

\section{References}

Boyer, E.L. (1990). Scholarship reconsidered: Priorities of the professoriate. New York, NY: Jossey-Bass.

Centre for Teaching Excellence, University of Waterloo. (2009). Certificate in university teaching program description. Retrieved from http://cte.uwaterloo.ca/graduate_pro- 
grams/CUT/CUT_902/CUT_902_rpa. html

Christensen Hughes, J. (2006). The scholarship of teaching and learning: A Canadian perspective. Retrieved from http://www.mcmaster. $\mathrm{ca} / \mathrm{stlhe} /$ documents/SoTLCanadianPerspectiveJan06.pdf

Ciccone, A. \& Meyers, R. (2006). Problematizing SoTL impact. ISSOTL Conference, University of Wisconsin-Milwaukee, Milwaukee, WI.

Gale, R. \& Golde, C.M. (2004). Doctoral education and the scholarship of teaching and learning. Peer Review, 8-12.

Huber, M.T. \& Hutchings, P. (2005). The advancement of learning: Building the teaching commons. San Francisco, CA: Jossey-Bass.

Kreber, C. (2001). The scholarship of teaching and its implementation in faculty development and graduate education. New Directions for Teaching and Learning, 86, 79-88.

McKinney, K. (2006). Attitudinal and structural factors contributing to challenges in the work of the scholarship of teaching and learning. New Directions for Institutional Research, 129, 37-60.

O’Meara, K.A. (2005). Encouraging multiple forms of scholarship in faculty reward systems: Does it make a difference? Research in Higher Education, 46, 479-510.

Shulman, L.S. (2004).Visions of the possible: Models for campus support of the scholarship of teaching and learning. In W.E. Becker \& M.L. Andrews (Eds.), The scholarship of teaching and learning in higher education (pp. 9-23). Bloomington, IN: Indiana University Press.
Werder, C. \& Otis, M. (Eds.). (2009). Engaging student voices in the study of teaching and learning. Sterling, VA: Stylus.

\section{Biography}

Natasha Patrito Hannon is an Educational Developer with the Teaching Support Centre (TSC) at The University of Western Ontario, where she coordinates instructional development programs for graduate students and faculty in scientific and engineering disciplines.

Svitlana Taraban-Gordon is a Senior Instructional Developer with the Centre for Teaching Excellence (CTE) at the University of Waterloo, where she coordinates instructional development programs for domestic and international teaching assistants. 